\title{
COVID-19 and concerns related to self-medication
}

\section{Sir,}

The practice of self-care through self-medication is not uncommon. ${ }^{1-3}$ Self-medication is not just a problem of one country, the phenomenon is global. ${ }^{4} \mathrm{~A}$ systematic review has highlighted this wide spread problem. ${ }^{5}$ Selfmedication can be based on self-belief, advice of a pharmacist or another person instead of consultation with a qualified healthcare professional. In the settings of poor access to health care services and issues related to affordability of paying for medical services, people practice self-medication as the righteous approach. Some people may consume medications without consultation of a healthcare professional citing reason of time saving. Certain drugs available as prescription medicine in one country may be available over the counter in another country. Furthermore, with digitalisation, people now have an easy access to the internet where they simply explore their symptoms and find the perceived suitable treatment for the same. Thus, the reasons and pattern of self-medications may differ based on different factors including type of population affordability, and country.

The reason for brining issue of self-medication for discussion here is the currently on-going COVID-19 pandemic. In this situation, the rates of self-medication are likely to be amplified because of several reasons. COVID-19 may further widen the problem of inadequate access of healthcare especially in countries with weak health systems. ${ }^{6}$ One, with the known risk of getting infected with virus, people are scared to visit a clinic or hospital believing that they might come in contact with an infected patient or contaminated objects. Secondly, because of lock-down in many places and restrictions on travel, those who want to visit hospital, are facing challenges to visit the hospitals. In some places, doctors have reduced their practice. Because of quarantine of healthcare professionals, healthcare services in some areas may have been hampered. Moreover, because of fear and desperation of protecting self, people may fall prey to unknown medicines claiming benefits against COVID-19. General population may try interventions derived from non-trustworthy sources and suffer from adverse events. ${ }^{7}$ All these reasons are over and above the traditional causes of self-medication. In an editorial commentary, Molento has expressed the concerns with self-medication with ivermectin. ${ }^{8}$

Unlike other aspects of self-care, self-medication involves the use of drugs. Although drugs are potentially beneficial, they can cause be a cause of great anguish in some patients. Individuals may consume medications on their own without any prior knowledge of medicines, making the situation challenging and increasing the risk of adverse events. Use of excessive dosage, prolonged duration of use, drug interactions, adverse reactions and antibiotic resistance are some of the known problems associated with misuse of medicines. Adverse events related to drugs can be immediate or delayed. Selfmedication in the long run, can lead to disastrous consequences if risk benefit ratio of medicine is not known. Many diseases have similar symptoms, and inappropriate treatment can exaggerate the condition. Prior knowledge of the health status is very important before consuming any medicine as there are many preexisting conditions in which certain drugs can be contraindicated, and when consumed, they can result in significant complications.

There is a need for increase in awareness about selfmedication among general population. ${ }^{9}$ Increasing awareness about the risk of adverse events related to drugs, guidelines and regulations related to use of different drugs can be useful to prevent adverse consequences related to self-medication. Everyone including physicians, pharmacist, community and government has a very important role to play in avoiding adverse implications related to self-medication all time, and more so now during COVID-19 pandemic.

\section{Anant D. Patil ${ }^{1 *}$, Hritika Sharma², Tanusri Tetarbe ${ }^{2}$}

${ }^{1}$ Department of Pharmacology, Dr. DY Patil Medical College and Hospital, Navi Mumbai, Maharashtra, India ${ }^{2}$ Dr. DY Patil Medical College and Hospital, Navi Mumbai, Maharashtra, India

*Correspondence to

Dr. Anant D. Patil,

E-mail: anantd1patil@gmail.com

\section{REFERENCES}

1. Kumar V, Mangal A, Yadav G, Raut D, Singh S. Prevalence and pattern of self-medication practices in an urban area of Delhi, India. Med J DY Patil Univ. 2015;8:16-20.

2. Sugumar R, Krishnaiah V, Channaveera GS, Mruthyunjaya S. Comparison of the pattern, efficacy, and tolerability of self-medicated drugs in primary dysmenorrhea: A questionnaire based survey. Indian J Pharmacol. 2013;45:180-3.

3. Kassie AD, Bifftu BB, Mekonnen HS. Selfmedication practice and associated factors among 
adult household members in Meket district, Northeast Ethiopia, 2017. BMC Pharmacol Toxicol. 2018;19:15.

4. Bennadi D. Self-medication: A current challenge. J Basic Clin Pharma. 2014;5:19-23.

5. Limaye D, Limaye V, Krause G, Fortwengel G. A systematic review of the literature to assess selfmedication practices. Ann Med Health Sci Res. 2017;7:1-15.

6. Kretchy IA, Asiedu-Danso M, Kretchy J-P. Medication management and adherence during the COVID-19 pandemic: Perspectives and experiences from low-and middle-income countries. Res Social Admin Pharma. 2020.

7. Newmann NR, Chai PR, Wood DM, Greller HA, Mycyk MB. Medical toxicology and COVID-19: Our role in a pandemic. J Med Toxicol. 2020.
8. Molento MB. COVID-19 and the rush for selfmedication and self-dosing with ivermectin: A word of caution. One Health. 2020;10:100148.

9. Patil AD. Self-medication: need for increased awareness among general population. Int J Basic Clin Pharmacol. 2013;2:659-60.

Cite this article as: Patil AD, Sharma $\mathrm{H}$, Tetarbe $\mathrm{T}$. COVID-19 and concerns related to self-medication. Int J Basic Clin Pharmacol 2020;9:1475-6. 